Revista Mídia e Cotidiano

ISSN: 2178-602X

Artigo Seção Temática

Volume 14, Número 3, set./dez. de 2020

Submetido em: 20/06/2020

Aprovado em: 16/08/2020

\title{
A pesquisa de grupos de direita: questões éticas e metodológicas
}

\author{
Researching right-wing groups: ethical and methodological issues
}

Investigando grupos de derecha: cuestiones éticas y metodológicas

\author{
Richard ROMANCINI ${ }^{1}$
}

\section{Resumo}

A pesquisa de grupos de direita possui desafios éticos e metodológicos, principalmente quando realizada em contexto digital, devido às caraterísticas do ambiente on-line, bem como se são abordados movimentos extremistas. O objetivo desse artigo é expor e debater alguns pontos críticos desse tipo de investigação, sob as dimensões mencionadas, utilizando como amparo experiências de pesquisa do autor e discussões científicas voltadas à questão da ética e da metodologia de pesquisa envolvendo grupos e movimentos de direita, verificadas a partir de revisão da literatura. Duas dimensões principais do tema são discutidas: 1) a relevância dos enquadramentos mais gerais para as investigações, em particular no espaço digital, e 2) o acesso aos grupos investigados e a questão do rapport a ser desenvolvido (ou não) com eles.

Palavras-chave: Ética. Metodologia. Pesquisa. Direita política.

\begin{abstract}
Researching right-wing groups possess ethical and methodological challenges, especially when carried out in a digital context, due to the characteristics of the online environment, as well as whether extremist movements are addressed. The aim of this article is to expose and debate some critical points of this kind of investigation, under the mentioned dimensions, using as support the author's research experiences and scientific discussions focused on the issue of ethics and research methodology involving groups and movements of the right-wing, found from a literature review. Two main dimensions of the issue are discussed: 1) the relevance of broader frameworks for the researches, particularly in the digital space, and 2) access to the investigated groups and the question of rapport to be developed (or not) with them.
\end{abstract}

Keywords: Ethics. Methodology. Research. Political right-wing.

\footnotetext{
${ }^{1}$ Professor do Programa de Pós-Graduação em Ciências da Comunicação da Universidade de São Paulo. E-mail: richardromancini@usp.br. ORCID: 0000-0002-1651-5880.
} 


\title{
Resumen
}

La investigación de grupos de derecha tiene desafíos éticos y metodológicos, especialmente si llevada a cabo en un contexto digital, debido a las características del entorno en línea, así como cuando son abordados movimientos extremistas. El objetivo de este artículo es exponer y debatir algunos puntos críticos de este tipo de investigación, bajo las dimensiones mencionadas, utilizando como apoyo las experiencias de investigación del autor y las discusiones científicas centradas en la cuestión de la ética y la metodología de investigación en relación con los grupos y movimientos de la derecha, ubicadas en una revisión de la literatura. Se discuten dos dimensiones principales del tema: 1) la relevancia de marcos más generales para las investigaciones, particularmente en el espacio digital, y 2) el acceso a los grupos investigados y la cuestión del rapport que se desarrollará (o no) con ellos.

Palabras clave: Ética. Metodología. Investigación. Derecha política.

\section{Introdução}

\begin{abstract}
A maioria dos pesquisadores de movimentos sociais gosta de fazer pesquisas que lhes fazem bem. Estudam movimentos progressistas de esquerda que apreciam e simpatizam, consideram esses estudos uma forma de solidariedade e tendem a simplesmente celebrar como esses grupos se organizam e se comunicam. [...] Negligenciam a análise de movimentos e grupos de direita que representam uma ameaça à democracia. E, portanto, este é o ponto cego dos estudos de mídia dos movimentos sociais (FUCHS, 2018, p. 393, tradução nossa).
\end{abstract}

Apesar da observação da epígrafe, a produção acadêmica sobre a direita tem crescido, em todo o mundo, nos últimos anos. A bibliografia compilada pelo Center for Analysis of the Radical Right ${ }^{2}$, que soma 243 e 656 artigos científicos, respectivamente, para os anos de 2016 e 2019, ilustra esse fato. Isso se deve à escalada global de eventos (Brexit, eleição de Trump, fenômenos como Orbán na Hungria e Bolsonaro no Brasil, entre outros) que colocaram variadas ideologias conservadoras no centro da esfera pública. Tais eventos se associam à recessão econômica em diversos países, desde 2007, e aos conflitos que geraram ondas migratórias e crises humanitárias (TOSCANO, 2019a).

Há, porém, lacunas na pesquisa de comunicação sobre os grupos de direita, e o mesmo ocorre no campo de estudo dos movimentos sociais (POULSON; CASWELL;

\footnotetext{
${ }^{2}$ Disponível em: http://www.radicalrightanalysis.com/bibliography/. Acesso em 25 abr. 2020.
} 


\section{míDiA

GRAY, 2014; KINCAID, 2017) ${ }^{3}$. Nesses âmbitos, os trabalhos sobre os grupos de esquerda são majoritários. Além dos motivos de afinidade destacados por Fuchs (2018), outras questões também influenciam essa situação. Entre elas, o tema central deste artigo: as dificuldades metodológicas e éticas da pesquisa com indivíduos e grupos de direita.

Nesse contexto, este artigo tem como objetivo discutir aspectos da ética e da metodologia de pesquisa desses grupos. As questões desenvolvidas estão associadas com uma experiência de pesquisa em andamento e, ainda, com outros trabalhos do autor. De modo a amparar a discussão, foi feita uma revisão de literatura sobre os temas em foco.

A reflexão se situa no marco da pesquisa em ciências sociais, e a especificidade em relação aos "grupos de direita" é de grau, não de gênero. Questões discutidas, como as do acesso do pesquisador aos participantes e das interações no campo, são desafios de qualquer investigação. Porém, como a experiência e a revisão de literatura demonstram, há ênfases diferentes na pesquisa da direita. Nela, por exemplo, se questiona a viabilidade e a validade do rapport - ou seja, a conexão entre o pesquisador e os participantes, caracterizada por aspectos como a empatia, desenvolvimento de confiança e, talvez, amizade (SMYTH; MITCHELL, 2007) -, enquanto na discussão mais ampla, em particular no contexto etnográfico, se debate um ponto, entre outros, sem reverberação nos estudos de primeiro tipo: o possível problema do excesso de rapport (over-rapport) (HAMMERSLEY; ATKINSON, 2007; HOOLACHAN, 2020).

Sobre a relevância do estudo dos movimentos de direita há argumentos voltados à análise crítica da sociedade, com a meta de combater extremismos e preconceitos de franjas radicais, como em Fuchs (2018), para que se promova algum tipo de mudança social (PILKINGTON, 2016, 2019), ou com o fim de conhecê-los para que as teorizações possuam maior validade e alcance. Assim, discutindo a categoria dos "movimentos estranhos" (awkward movements) ${ }^{4}$, Snow (2006, p. 497, tradução nossa) observa que:

${ }^{3}$ No caso brasileiro, Fernandes e Messenberg (2018) observam que a sociologia local não desenvolveu uma tradição de estudos sobre a direita política, por isso, o adjetivo "nova" é, de maneira recorrente, aplicado a ela, já que o tema sempre parece uma novidade. É o caso dos trabalhos de Pierucci (1987, 1999). Há, entretanto, alguns elementos "novos" na direita brasileira atual, conforme se discute adiante.

${ }^{4}$ É interessante notar a variedade de termos que a literatura registra a propósito dos grupos e movimentos malquistos: "anti-social" (WIEVIORKA, 2019), "distasteful” (ESSEVELD; EYERMAN, 1992), "ugly” (GILLAN; PICKERILL, 2012) e “unloved” (WALDNER; DOBRATZ, 2019). 
Se não estudamos esses movimentos tão comumente como fazemos com aqueles com os quais simpatizamos ou nos identificamos, não há nenhuma maneira de estabelecer, realmente, o leque dos tipos de movimentos e de saber se alguns deles são mais comuns ou modais do que outros. E, como resultado, é provável que nossas pressuposições teóricas e generalizações empíricas sejam distorcidas e, portanto, equivocadas.

Ao mesmo tempo, refletir sobre a ética na pesquisa de grupos de direita auxilia a feitura de trabalhos mais reflexivos e pode permitir o crescimento dos estudos. Como notam Hammersley e Atkinson (2007), pesquisas questionadas eticamente pelos participantes fecham portas, mas, se ocorre o contrário, podem favorecer outros trabalhos.

\section{Ética e método na investigação científica}

Para Markham (2006), método e ética se entrelaçam em toda pesquisa. Entendido amplamente como o conjunto de reflexões e procedimentos para o desenvolvimento da investigação, o "método" possui implicações éticas. Já a ética, ao envolver os "valores, regras e práticas que devem guiar os pesquisadores na realização de seu trabalho" (ROMANCINI, 2010, p. 2), encontra na prática metodológica sua concretização. "Muito rápido, na verdade imediatamente, a ética, quando praticada, tornase uma questão de método. Da mesma forma, ao agirmos, todas as nossas escolhas têm consequências éticas" (MARKHAM; TIIDENBERG; HERMAN, 2018, p. 2, tradução nossa).

Entretanto, existe outra dimensão - além dessa estritamente "metodológica" que constitui um eixo de problematização da ética de pesquisa, como discute Ferreira (2013). A partir de um ponto de vista ontológico e epistemológico, há também um tipo de questionamento que busca "problematizar a posição do investigador face ao objeto de estudo - o 'social' - e avaliar a relação que existe entre conhecimento e interesses" (FERREIRA, 2013, p. 171). Essa problemática ética pode ser sintetizada na indagação, sobretudo de objetos menos tradicionais: por que pesquisar isso?

Do ponto de vista metodológico e ético, as dificuldades fazem com que os movimentos de direita sejam geralmente estudados com distanciamento: a partir de dados de jornais, sites da internet, discursos públicos e fontes policiais (BLEE, 2007). Falando dos movimentos de extrema-direita, Toscano (2019a) nota que, além dos desafios 
específicos da investigação, diferenças ideológicas e políticas entre pesquisadores e pesquisados constituem obstáculos. Desse modo, uma "ética de imediata reciprocidade" (GILLAN; PICKERILL, 2012) pode ser difícil. Nesse embasamento, comum em trabalhos em que há convergência de valores entre o pesquisador e o grupo pesquisado, predominam a empatia, eventual colaboração e a intersubjetividade nas interações.

O leque de posicionamentos ideológicos da "direita" é amplo. Porém, é principalmente em relação aos grupos que se associam ao "mau", nos termos de Wieviorka (2019), que os problemas éticos se tornam mais agudos. Para esse autor, o "mau" não representa uma categoria metafísica ou religiosa, mas sim o reconhecimento e negação da subjetividade e da humanidade de um indivíduo ou grupo diferente. Isso envolverá, assim, apreço por ideias e práticas (racismo, sexismo, homofobia etc.) com as quais o pesquisador dificilmente poderá concordar.

Na próxima seção, descreve-se, em traços gerais, o estudo do qual se retiram indagações a serem discutidas, com apoio da literatura da revisão. Tendo em vista o objetivo principal do texto, não são detalhados marcos teóricos ou resultados, pois o interesse é mostrar o contexto de pesquisa em que os questionamentos éticos surgiram.

\section{Os universitários de direita}

Quando minha assistente de pesquisa e eu fomos ao " $1{ }^{\circ}$ Encontro da União Nacional dos Estudantes Conservadores", sentíamos um misto de ansiedade e expectativa. Como seríamos recebidos? Fomos informados de que haveria atraso no início do evento e aproveitamos o tempo para repassar o que havíamos combinado sobre nossa identificação: não iríamos mentir, e diríamos que éramos pesquisadores com interesse em obter o contato de estudantes conservadores. Quando chegou a hora e voltamos ao local, entramos numa fila em que houve a identificação dos participantes e, para nossa surpresa, revista a todos, por um jovem de porte atlético que vestia calça em estilo militar. Já na ampla sala do andar em que se daria o encontro, a experiência de controle foi substituída por um ambiente de camaradagem e apresentações musicais introdutórias. O hino nacional foi executado por um violinista e, depois, houve um pequeno show de rock, realizado por uma dupla, que intercalou clássicos do gênero e músicas com mensagens conservadoras. A cantora procurava infundir vibração e ânimo à apresentação. Ao fim da canção "Whole lotta love", entre aplausos, agradeceu a plateia e indagou: "Quem disse que conservador não pode ser roqueiro?” (Diário de campo, 16 mar. 2019). 
A pesquisa em andamento, relacionada à descrição, volta-se ao âmbito pouco conhecido dos universitários brasileiros de direita - no caso, de uma universidade pública de prestígio. O foco são os usos e consumos midiáticos desses estudantes, em termos das relações dessas práticas com a opção/formação ideológica e eventual ativismo, bem como a experiência propriamente estudantil. A investigação possuía, no início, um plano de abordagem qualitativa a partir de entrevistas em profundidade.

A localização de participantes a partir da consulta a estudantes conhecidos não deu resultado. Isso inviabilizou a ideia de amostragem "bola de neve", na qual um informante indica outro(s). Por isso, buscou-se espaços digitais de universitários de direita, em geral, e da universidade de interesse, em que estratégias de convite fossem possíveis. Foi desse modo que se chegou à página de Facebook da "União Nacional dos Estudantes Conservadores" (UNECON), que promovia seu primeiro encontro.

Assim, nos inscrevemos no evento, realizado na cidade de São Paulo, com a expectativa de encontrar os estudantes da universidade desejada e convidá-los a participar da pesquisa. Houve, aqui, a decisão ética de realizar uma observação não dissimulada, declarando a condição de investigadores. Embora as observações tenham sido ricas, sendo percebida a tentativa desses universitários de elaborar uma identidade com linguagem "modernizada", nenhum aluno da universidade de interesse esteve presente. $O$ organizador do encontro, o deputado estadual Douglas Garcia (PSL-SP), disse que um problema de locomoção impediu a participação desses estudantes.

Outras páginas de Facebook, diretamente ligadas a estudantes da universidade, foram mapeadas, e três delas - referidas a partir de agora como A, B e $\mathrm{C}^{5}$ (para preservar o anonimato dos entrevistados, cuja associação com tais páginas, por vezes, é significativa) - pareceram promissoras para a localização de contatos. Eram páginas públicas, mas evitou-se realizar interações visíveis a todos, para não provocar possível mal-estar nos participantes. O que se fez foi escrever mensagens para os administradores, solicitando a publicação, por eles, de uma postagem na qual era feito o convite para a participação na pesquisa. O texto tinha um link para um breve questionário, cujas

${ }^{5}$ Elas foram criadas, respectivamente, em 2016, 2017 e 2018. A página A tem o maior número de seguidores, cerca de 220 mil, e as outras bem menos: 6 mil (B) e 15 mil (C). 
perguntas permitiam obter informações básicas do estudante e, como pergunta final, a indagação sobre a disponibilidade para uma entrevista pessoal. Os moderadores das páginas $\mathrm{A}$ e $\mathrm{B}$ concordaram em fazer isso, e um dos criadores da página $\mathrm{A}$ chegou a conceder entrevista. Além disso, se comprometeram a divulgar o questionário em grupos de WhatsApp de perfil similar.

Sobre esse processo inicial de obtenção de dados e convites para entrevistas, é válido descrever uma situação significativa. Num primeiro momento, durante o ano de 2019, foram enviadas as mensagens para as páginas mencionadas e outras. No entanto, apenas 28 questionários retornaram. A situação se alterou após uma estudante de graduação que possuía conhecidos de centros acadêmicos da universidade ter divulgado o link do questionário, sendo que alguns dos contatos dela eram estudantes de direita. Então, em poucos dias do mês de junho de 2020, obteve-se um número elevado de respostas: cerca de 220 questionários válidos. É provável que dois fatores, combinados, expliquem isso: a época de isolamento social, devido à pandemia, em que se transmitiu o questionário, de modo que pessoas em casa, com mais tempo, se sentiram estimuladas a responder; e a forma com que o link chegou a elas, por meio de alguém de confiança. Esse último aspecto destaca a importância, de modo geral, da mediação de indivíduos que possuem relação com os participantes, para que o pesquisador obtenha acesso ou dados de um grupo, conforme, inclusive, será aprofundado adiante.

Voltando a falar das páginas de Facebook mencionadas, as postagens feitas nelas eram visualizadas, o que permitiu perceber formas de expressão da direita universitária. Tornou-se, então, evidente a pluralidade de posições, o que se relaciona com a natureza do termo "direita", já que ele, como observa Velasco e Cruz (2015, p. 14), "não remete a uma corrente de pensamento particular, nem sequer a uma família de pensadores, de partidos ou movimentos políticos e sociais". Por isso, a "direita" assim como seu par dicotômico, a "esquerda", comporta ideologias diversificadas.

\section{Variedades da direita no Brasil e questões de pesquisa}

No leque que vai da "direita" à "extrema-direita", as pesquisas que buscam mapear o panorama atual brasileiro falam da emergência, no sistema partidário, de uma "nova direita" em oposição a uma "velha direita" (CODATO; BOLOGNESI; ROEDER, 
2015), tendo como principal ponto de cisão a defesa/ligação da primeira com a ditatura de 1964, enquanto a mais atual defende a democracia. Já Messenberg (2017, p. 633) nota que a cosmovisão da direita no Brasil atual deve ser "compreendida como um universo multidimensional, o qual abarca diferentes tonalidades ideológicas e emissões discursivas". Com essa ressalva, a autora identifica alguns campos semânticos antipetismo, conservadorismo moral e princípios neoliberais - dessa direita.

Aqui, vale retomar a discussão sobre a "nova direita" no país hoje. Como se disse (vide nota 3), ela parece ter, ao menos, dois elementos inovadores. O primeiro é a sua exposição pública - a metáfora de uma direita que "saiu do armário" é comum em textos jornalísticos e acadêmicos -, associada à disposição para a luta ideológica e cultural (CEPÊDA, 2018). A tentativa de se formar a "União Nacional dos Estudantes Conservadores" deve ser vista nessa moldura. O segundo aspecto "novo" é a conquista do poder, pela via eleitoral. No caso, um candidato da "direita radical", Jair Bolsonaro, que combina autoritarismo e neoliberalismo, substituiu, na preferência dos eleitores, os candidatos da "direita moderada" (SANTOS; TANSCHEIT, 2019).

Ressaltando a diversidade de posicionamentos da direita brasileira atual, com base no tipo de conteúdo das página de Facebook, é possível caracterizar a B como liberal (pró-descriminalização das drogas, por exemplo) em termos de costumes e liberal em economia; a A, como menos liberal (com postagens antifeministas, por exemplo) que a $\mathrm{B}$ em costumes, mas igualmente próxima do liberalismo econômico; já a página $\mathrm{C}$ é conservadora nos costumes (ou ultraconservadora, com postagens que debocham dos direitos humanos) e ultraliberal em termos econômicos. É com essa página que o contato foi mais difícil, evidenciando a questão ética e metodológica do acesso aos participantes.

Nesse caso, também se escreveu para os administradores, mas não houve resposta inicial, e então, após algum tempo, foi feita outra tentativa. De novo sem resposta. Depois, a página $\mathrm{C}$ publicou uma postagem na qual alertava seus leitores para não responder nenhuma pesquisa "para sua própria segurança". Nossa mensagem e o link do questionário eram mostrados como um exemplo de "arapuca" representada por mapeamentos dos universitários de direita. Informava-se, nesse sentido, que uma lista de estudantes desse tipo provocara perseguições numa das faculdades da universidade. 


\section{míiA
eCOti
DiAno}

Solicitava-se, por fim, que a mensagem fosse compartilhada para maior divulgação. Numa situação desse tipo, como o pesquisador deve reagir?

Por outro lado, obter o contato e interagir com os indivíduos conduz ao tema do rapport e, por isso, à relação entre a qualidade das interações com a construção de conhecimento. A literatura pode amparar planejamentos, mas há sempre uma margem de incerteza pela natureza emergente da pesquisa qualitativa. Desse modo, o pesquisador tende a ser mais genérico em sua explicação aos participantes sobre o teor da pesquisa, não somente por que isso poderá induzir comportamentos, mas também por que não tem certeza, desde o início, de tudo o que envolve a investigação. Ao mesmo tempo, ainda que seja válido considerar a reflexão sobre a relevância, igualmente estratégica e ética, do pesquisador fornecer informações sobre si mesmo aos participantes, é difícil estimar "o quanto de desvelamento é apropriado e sobre o quê" (HAMMERSLEY; ATKINSON, 2007, p. 108, destaque no original, tradução nossa).

Assim, vale descrever a situação de uma das primeiras entrevistas qualitativas, realizada há cerca de um ano. A informação de que o pesquisador é professor já era dada no questionário prévio, no entanto, é reforçada na conversa que antecede as entrevistas, nas quais se fala ainda das preocupações gerais do estudo, do compromisso com o anonimato dos participantes e da confidencialidade das informações. Porém, o estudante, ao fim do diálogo, quis saber mais e indagou: "E você, você como professor, é conservador?". O tom foi mais curioso do que agressivo - a conversa tinha sido amistosa -, e a pergunta talvez fosse prova de um rapport bem-sucedido.

Embora, de certo modo, surpreendido pela pergunta, logo respondi que me definiria como "de esquerda", embora tendo, na pesquisa realizada, um interesse, sobretudo, compreensivo. Ao fim da conversa, pensei que a resposta poderia ter me custado o acesso a muitos informantes (o entrevistado era administrador de uma das páginas do Facebook, tendo provavelmente muitos contatos). Não sei se isso ocorreu ou não. No entanto, o fato de que os participantes podem querer trocar de papel com o pesquisador importa. Fiz bem ou mal, ao responder de maneira honesta à pergunta?

Parece interessante inserir indagações como as expostas num questionamento mais amplo. Nesse sentido, são elaboradas duas questões de pesquisa, a serem analisadas, a partir da revisão bibliográfica, conforme se segue: 
1. A literatura indica enquadramentos éticos mais gerais para o estudo de grupos de direita?

2. Como são vistas as questões do acesso e do rapport na pesquisa de tais grupos?

\section{Metodologia da revisão de literatura}

Para coletar trabalhos que discutem as questões, foram consultadas bases de $\operatorname{dados}^{6}$ e feitas buscas no Google Acadêmico. As palavras-chave utilizadas foram: research, ethics e right-wing. Vale notar que o uso de outras palavras-chave, com o qual o tema tem certa afinidade (como sensitive topics e risk, no lugar de right-wing), poderia fazer com que fossem recuperados diferentes textos, já que há trabalhos sobre essas questões. Porém, incluir expressões desse tipo poderia gerar perda de foco no estudo.

O critério para a escolha e a leitura integral dos textos (após a verificação dos resumos) foi a existência de efetiva articulação entre os três termos nos trabalhos, sendo que o termo research foi entendido como associado à pesquisa científica, acadêmica.

A partir do exposto, chegou-se a 22 trabalhos - 13 artigos e nove capítulos de livros -, mostrados na tabela a seguir, que foram lidos e são usados na discussão.

Tabela 1 - Trabalhos coletados para a revisão de literatura

\begin{tabular}{lll}
\hline \multicolumn{1}{c}{ Geral } & \multicolumn{1}{c}{ Foco na internet } \\
\hline Artigo & Blee (1993, 1998, 2006, 2007) & Askanius (2019) \\
& Blee e Creasap (2010) & Massanari (2018) \\
& Eriksson (2016) & Rambukkana (2019) \\
& Seidman (2006) & \\
& Smyth e Mitchell (2008) & \\
& Snow (2006) & \\
& Tyagi (2018) & Fuchs (2018) \\
& & Schaffar e Thabchumpon (2019) \\
Capítulo de livro & Bizeul (2019) & \\
& Pilkington (2016, 2019) \\
& Toscano (2019a) & \\
\hline
\end{tabular}

\footnotetext{
${ }^{6}$ A saber: EBSCO (Academic Search Premier, Business Source Complete, Educational Administration Abstracts, Historical Abstracts, Human Resources Abstracts, Information Science \& Technology Abstracts, Public Administration Abstracts, Urban Studies Abstracts), JSTOR (Arts and Sciences I, Arts and Sciences III e XIV), ProQuest (Applied Social Sciences Index \& Abstracts, ERIC, Sociological Abstracts), Scopus, Sage e Taylor \& Francis. Quase todas essas bases cobrem a área da comunicação, o que justificou seu uso.
} 
Toscano; Di Nunzio (2019)

Waldner e Dobratz (2019)

Wieviorka (2019)

Fonte: Elaboração do autor.

Sem a pretensão de fazer uma análise do todo, é válido notar: a importância da pesquisadora estadunidense Kathleen Blee, que possui vasta e pioneira produção na temática; o relevo contemporâneo da discussão (14 estudos são dos últimos cinco anos); a ênfase no debate ético-metodológico da pesquisa qualitativa - a exceção parcial é o trabalho de Rambukkana (2019); o fato de que alguns trabalhos (cinco) têm foco específico em questões da pesquisa na internet, sendo, não por acaso, textos recentes; e o número relevante de capítulos de livros, em parte, pelos trabalhos da coletânea organizada por Toscano (2019), com um panorama global da pesquisa sobre a temática.

Feita essa caracterização, a seguir são discutidas as questões já expostas.

\section{Um enquadramento ético geral para a pesquisa}

As grandes molduras éticas sob as quais são desenvolvidas as reflexões que informam as éticas específicas para o mundo digital e para a pesquisa (utilitarismo, deontologia, feminismo etc.) (ESS, 2009) permitem derivar julgamentos práticos para a condução de investigações. No entanto, há problemas entre certas inferências dessas éticas, quando são aplicadas a determinados grupos de direita (principalmente, os que se associam ao "mau"). Assim, por exemplo, a "ética da reciprocidade", preconizada pelo paradigma ético feminista, é inviável na pesquisa de militantes antifeministas.

Ao mesmo tempo, ainda que seja importante reconhecer o valor da abordagem ética situacional - ou seja, a que procura desenvolver juízos para tomada de decisão, guiados por princípios como o respeito pelos indivíduos pesquisados, a justiça e a beneficência, a partir de contextos específicos de pesquisa (MARKHAM; TIIDENBERG; HERMAN, 2018) -, tal abordagem pode ser favorecida por marcos éticos gerais.

Nesse sentido, observa-se que, na revisão empreendida, localiza-se no texto de Fuchs (2018) a principal tentativa para o desenvolvimento de um instrumento reflexivo desse tipo, principalmente para a pesquisa qualitativa no ambiente on-line. Para tanto, o autor discute alguns códigos de ética de pesquisa, mostrando as limitações dos mesmos; 
e depois, descreve as características do que chama de "ética crítico-realista para a pesquisa na internet" (FUCHS, 2018, p. 386).

A crítica central do autor aos códigos de ética reside na ideia de que eles prestam pouca atenção à pesquisa on-line. Assim, não há discussões que encaminhem práticas realistas sobre o significado do que é "público" ou "privado" no ambiente digital, bem como sobre a dificuldade de manutenção do anonimato dos participantes nesse espaço, tendo em vista que os dados citados - como tweets armazenados em servidores - são recuperáveis por ferramentas de busca. O primeiro aspecto é discutido com frequência na literatura sobre a ética de pesquisa no contexto on-line, e comparece nas discussões de trabalhos da revisão efetuada, como o de Schaffar e Thabchumpon (2019).

O que é central nessa questão, em termos da normativa ética, é quando a obtenção de consentimento informado dos participantes é necessária. Se sempre, o que fazer quando uma base de dados de pesquisa possui milhares de tweets de pessoas? Igualmente problemático, no caso da pesquisa com grupos de direita, seria o pedido, conforme o título do trabalho de Fuchs (2018): "Caro Sr. Neo-Nazi, você pode me dar, por favor, o seu consentimento informado para que eu cite seu tweet fascista?".

É claro, a pergunta é irônica e serve para ilustrar as limitações do atual estado dos guias éticos. Dentro do entendimento mais usual, apenas a pesquisa de grandes dados (big data) agregados e, portanto, anônimos ${ }^{7}$, seria "eticamente responsável”. "Mas essa abordagem é enviesada para os métodos quantitativos e ciências sociais computacionais. A análise crítica do discurso e a pesquisa crítica interpretativa se tornariam, assim, impossíveis" (FUCHS, 2018, p. 389, tradução nossa). Vale dizer, entretanto, que a própria pesquisa quantitativa no ambiente on-line apresenta questões éticas complexas e polêmicas, como no caso do experimento de "contágio emocional", pela manipulação de postagens do Facebook (KRAMER; GUILLORY; HANCOCK, 2014).

Retornando à discussão de Fuchs (2018), para ir além do "fundamentalismo ético" e do "positivismo" quantitativista, o autor propõe um enquadramento ético para a pesquisa on-line de natureza qualitativa e crítica, com base na avaliação sobre a

${ }^{7}$ A noções de anonimato e a de confidencialidade (ou seja, a proteção das informações dadas) buscam proteger os participantes de pesquisas, garantindo a privacidade dos mesmos, e são um consenso em termos das normas e regulações éticas (cf. ROMANCINI, 2010, p. 5). 


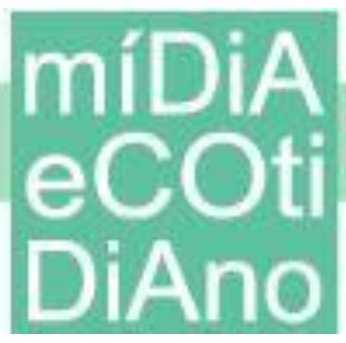

expectativa dos usuários de mídia social sobre a privacidade. Assim, dados de grupos ou fóruns digitais fechados, por exemplo, exigiriam considerações éticas mais aprofundadas. No entanto, isso não seria necessário no caso de espaços digitais nos quais exista a ideia de comunicação para públicos amplos (embora se recomende que seja omitida a identidade do autor do dado, exceto para figuras públicas). O uso de hashtags, para o autor, chega, na prática, a caracterizar o caráter "público" da mensagem, na medida em que os usuários da mídia social podem esperar (e desejar), de maneira razoável, ser observados por desconhecidos. Essa estrutura ética pode ser sintetizada como se segue.

Tabela 2 - Enquadramento ético crítico-realista para pesquisa

\begin{tabular}{|c|c|c|}
\hline & $\begin{array}{l}\text { Observação/Dados públicos } \\
\text { (por exemplo, grupos } \\
\text { abertos de plataformas } \\
\text { digitais) }\end{array}$ & $\begin{array}{l}\text { Observação/Dados privados } \\
\text { (por exemplo, grupos } \\
\text { fechados de plataformas } \\
\text { digitais) }\end{array}$ \\
\hline $\begin{array}{l}\text { Consentimento informado } \\
\text { dos produtores dos dados }\end{array}$ & Não necessário & $\begin{array}{l}\text { Possivelmente necessário, mas } \\
\text { requerendo reflexões }\end{array}$ \\
\hline $\begin{array}{l}\text { Anonimato dos } \\
\text { produtores dos dados } \\
\text { usados }\end{array}$ & Sim, para figuras não públicas & $\begin{array}{l}\text { Possivelmente necessário, mas } \\
\text { requerendo reflexões }\end{array}$ \\
\hline
\end{tabular}

Fonte: Adaptado de Fuchs (2018).

É válido notar que os relatos de investigações da mídia on-line nos trabalhos da revisão de literatura adotam decisões parecidas com a desse enquadramento. É o caso da observação de espaços digitais abertos de uma organização neonazista sueca, por Askanius (2019), ou os grupos de Facebook de "vigilantes" conservadores da Tailândia (SCHAFFAR; THABCHUMPON, 2019). Em minha experiência, a partir de uma reflexão situada, cheguei a uma conclusão (mesmo sem conhecer essa proposta) similar sobre a pertinência ética de coletar conversações públicas no Twitter (que usavam hashtags) com temas da direita, ocultando a identidade dos indivíduos comuns (ROMANCINI, 2018; ROMANCINI; CASTILHO, 2019).

É digno de nota que, embora a proposta de Fuchs (2018) esteja ligada à pesquisa qualitativa on-line, ela pode ser útil de maneira geral. Assim, a possibilidade de uso de dados públicos sem requerer consentimento informado, também em contexto off-line, 
aparece em alguns trabalhos da revisão que optaram por acompanhar manifestações públicas como passeatas (por exemplo, PILKINGTON, 2016 e WALDNER; DOBRATZ, 2019). Ao mesmo tempo, discute-se a possibilidade de que, mesmo na pesquisa que utiliza grandes dados, os participantes possam ser identificados (RAMBUKKANA, 2019), de modo que esse aspecto deve ser levado em conta. Enfim, a análise contextualizada deve refinar o uso do enquadramento sugerido.

\section{Acesso e rapport}

O acesso a indivíduos, grupos, movimentos e instituições que se deseja estudar é o primeiro passo para se obter dados em determinado contexto, enquanto o rapport está ligado à qualidade do relacionamento com os indivíduos. Entretanto, ambas as noções são profundamente relacionadas, pois o acesso vai além da mera permissão para a presença física ou perceptível do investigador em algum local; na pesquisa, ele exige interações, condizentes com os fins do estudo, entre os indivíduos (HAMMERSLEY; ATKINSON, 2007). Waldner e Dobratz (2019) defendem que o acesso e o rapport são dimensões que se reforçam mutuamente; uma vez que o pesquisador consegue o acesso inicial, poderá, pela construção do rapport, obter acesso a outros espaços privados do grupo investigado, assim como fazer indagações sobre temas mais sensíveis.

Em perspectiva similar, Toscano (2019a) nota que os pesquisadores da extremadireita enfrentam duas dificuldades principais: a negociação de acesso aos grupos que desejam investigar e o posicionamento do pesquisador no campo, com a sua complexa dinâmica emocional de relacionamento. De fato, destacando a importância dessas questões, a maioria dos textos vistos na revisão acaba tocando em algum desses pontos.

Os membros de grupos estigmatizados têm forte sensibilidade à intrusão de investigadores, pelo receio de serem retratados a partir de estereótipos ofensivos; por outro lado, podem querer ser mostrados de modo "justo", diferentemente de como aparecem na mídia, por exemplo, favorecendo a pesquisa (PILKINGTON, 2016). Em um contexto como o brasileiro, no qual existe estigma sobre os posicionamentos de direita pela associação com o período autoritário mais atual, em particular - pode-se dizer que, muitas vezes, mesmo indivíduos que adotam posições moderadas podem ter receio de se expor. As respostas dos estudantes ao questionário de nossa pesquisa, bem como as 


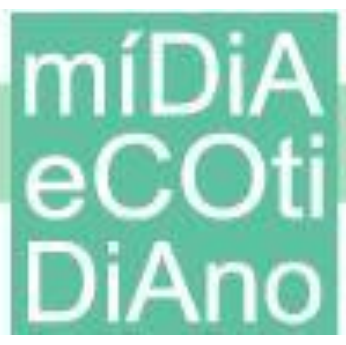

entrevistas realizadas até o momento, atestam isso. Nesse sentido, está sendo válido enfatizar o caráter anônimo da participação, como já se disse.

As duas questões críticas mencionadas por Toscano (2019a) afetam a viabilidade e a qualidade das análises "internalistas" da direita (GOODWIN, 2006), que destacam pontos como a organização interna dos movimentos/partidos e a participação de lideranças e ativistas. Requerem, assim, envolvimento maior com os participantes. A importância dessa abordagem está na tentativa de superar (ou complementar) as análises macroestruturais "externalistas" que utilizam variáveis sociais e dados eleitorais.

A perspectiva "internalista" depende não apenas do acesso aos grupos, mas da construção de relações interpessoais que favoreçam o desenvolvimento da investigação. Isso se dá em todo tipo de pesquisa, no entanto, possui particularidades no trabalho que se volta à política e com a direita. Sabe-se que os aspectos identitários (gênero, etnicidade, idade) e subjetivos (valores e opiniões) do pesquisador influenciam esse objetivo (HAMMERSLEY; ATKINSON, 2007). Blee (1993) discute como, em sua pesquisa com antigos membros da Ku Klux Klan, o fato de ser uma mulher branca, nascida no estado de Indiana, favoreceu a obtenção de dados. Os entrevistados, por essas características da pesquisadora, tendiam a acreditar que ela, ao menos secretamente, concordava "com as visões de mundo racistas e preconceituosas deles" (BLEE, 1993, p. 640, tradução nossa), apesar das declarações em contrário da autora.

Deve-se matizar, porém, a dicotomia entre pesquisas externalistas e internalistas. Embora a maioria dos trabalhos da revisão estejam, pelo viés qualitativo, mais próximos do segundo tipo, o acesso e a "proximidade" com o grupo podem ser relativos, por exemplo, quando apenas conteúdos on-line públicos são estudados. Num caso assim, Askanius (2019, p. 879) observa ter adotado uma perspectiva "interna", ao mesmo tempo em que "à distância". Isso afeta o conhecimento, pois, como indaga a autora: "Qual é a qualidade e a validade do material que coletamos desses espaços digitais e o que podemos deduzir de 'textos' destinados a persuadir e provocar?" (ASKANIUS, 2019, p. 881, tradução nossa). O ponto principal é que, nos espaços públicos (digitais ou não), qualquer grupo mostra uma face "editada" de sua identidade. Ao final do encontro dos estudantes conservadores brasileiros descrito, os participantes resolveram tirar a tradicional foto de congraçamento. Da primeira vez, expressões de satisfação e sorrisos; depois, em nova 


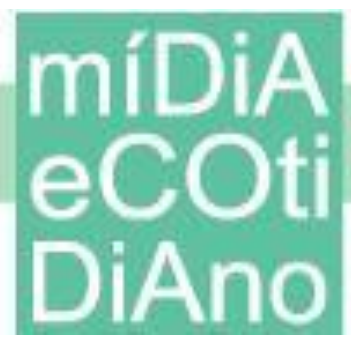

tomada, eles fizeram também o gesto da "arminha", típico de Bolsonaro. Essa versão, porém, não foi divulgada na mídia social, exemplificando o que foi dito.

De qualquer modo, os textos da revisão defendem que, quando a observação exige negociações com um grupo, o pesquisador procure obter acesso aos indivíduos sendo honesto quanto aos seus valores e aos objetivos do estudo - na medida do possível, ou seja, alguns sendo mais claros sobre isso do que outros. Assim, há autores que procuram negociar o acesso sem mentir, mas "sem contar toda a verdade", como no caso da pesquisadora que buscou, nem sempre com sucesso, apresentar-se como "neutra" em relação ao aborto (SMYTH; MITCHELL, 2008, p. 449).

A possibilidade de que certos grupos, organizações e indivíduos (de confiança dos participantes) colaborem no acesso do pesquisador é destacada em trabalhos, como o de Tyagi (2018). Na discussão da pesquisa etnográfica mais geral, termos como "guardiões" (gatekeepers) e "colaboradores" (sponsors) são usados para se referir a esses indivíduos (HAMMERSLEY; ATKINSON, 2007, p. 59).

Por outro lado, a polêmica observação dissimulada ou encoberta de indivíduos em situações face a face, rara na pesquisa social - o estudo de Lauder (2003) é uma exceção -, no contexto de um mundo no qual as fronteiras da intimidade foram remodeladas pela mídia social, tende a se tornar inviável, como discutem Toscano e Di Nunzio (2019), e por isso não tem destaque nos trabalhos lidos.

Nota-se controvérsia sobre a questão do rapport: nem todos os pesquisadores concordam com a sua necessidade. Isso transparece na revisão, com trabalhos, como o de Waldner e Dobratz (2019), favoráveis, enquanto outros avaliam que ele é desnecessário (BLEE, 1993) e há, ainda, os que adotam posições intermediárias.

Os defensores do rapport acreditam que ele pode ser uma forma de obter melhores dados, permitindo maior compreensão dos fenômenos. Porém, essa noção também é vista como superestimada na pesquisa social, já que, embora possa ser útil para entender algo, nem sempre é imprescindível, pois, como notam Smyth e Mitchell (2008, p. 444, tradução nossa), “a compreensão é alcançada através da linguagem, conversação e reflexão, não através de encontros empáticos". Desse modo, as autoras concluem que abordagens mais reflexivas, que considerem as subjetividades dos envolvidos, assim 


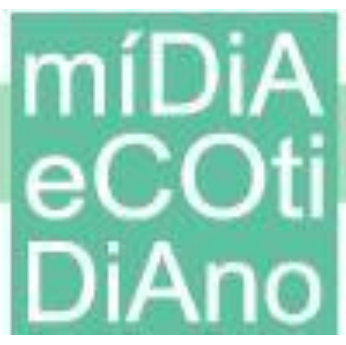

como a jornada emocional da pesquisa, podem, muitas vezes, substituir o rapport tradicional.

Waldner e Dobratz (2019) fazem uma observação relevante, principalmente caso se procure desenvolver rapport: que o investigador tente visualizar terrenos comuns de experiência entre ele e os indivíduos pesquisados, pois os seres humanos são complexos e possuem mais similaridades do que diferenças, quando se busca olhar as práticas sociais de maneira mais ampla. Isso não significa concordar (ou fingir concordar) com os valores políticos dos indivíduos, mas faz com que o pesquisador procure moderar suas declarações de discordância, sendo respeitoso com o participante e, com foco no objetivo de compreensão, podendo tentar assumir a perspectiva do indivíduo ou grupo investigado. Na pesquisa com os universitários de direita, um "terreno comum" é o diálogo sobre a experiência universitária, com os pedidos de esclarecimento sobre como o posicionamento político afeta a trajetória do estudante.

\section{Considerações finais}

É válido fazer aqui uma síntese sobre as questões de pesquisa, relacionando o que se percebeu em relação a aspectos que podem ser úteis a desdobramentos futuros do trabalho e também a outros investigadores.

Assim, a identificação da "ética crítico-realista" proposta por Fuchs (2018) foi valiosa, não só ao reforçar determinadas opções, mas ao indicar possibilidades em outros âmbitos. A observação de espaços on-line fechados é um exemplo desse tipo, que, como o autor discute, requer avaliações adicionais. Há trabalhos com essa característica, que podem favorecer a reflexão, como o de Hård Af Segerstad et al. (2017), que estuda um grupo de autoajuda do Facebook de pais que lidam com a perda de filhos. Como a observação explícita poderia perturbar os participantes, houve uma negociação com os administradores. Os pesquisadores obtiveram o consentimento informado deles, num acordo envolvendo o retorno de resultados da investigação para beneficiar os pais. No campo da política, há o exemplo de uma investigação sobre um grupo de WhatsApp de ativistas de esquerda. Nesse trabalho, no início, um dos autores publicou uma postagem no grupo, informando a natureza de sua participação e sobre o possível convite para entrevista, estratégia similar à recomendada por Kozinets (2010), em sua proposta de 


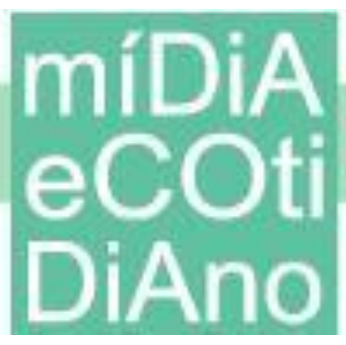

"netnografia". Curiosamente, com o tempo, os membros do grupo passaram a sentir que o pesquisador "agia como sua 'voz' e 'representante' dentro da academia e acolhiam com entusiasmo informações sobre, por exemplo, as apresentações públicas da pesquisa" (BARBOSA; MILAN, 2019, p. 54, tradução nossa). O quanto essa proximidade entre o pesquisador e os participantes pode favorecer ou não a pesquisa, é matéria de discussão. Entretanto, isso nos leva à questão de pesquisa seguinte, relacionada ao acesso e ao rapport na investigação de grupos de direita.

Ambos os aspectos, particularmente o primeiro, são centrais nos textos da revisão. O tema do rapport, de certo modo, se mostrou mais controverso e sujeito a debates. A comum dissonância ideológica entre os pesquisadores e os participantes de movimentos de direita é o cerne da complexidade imediata que envolve a questão. Porém, situando-se no contexto mais amplo das relações que se estabelecem entre pesquisadores e grupos pesquisados, a temática possui outras camadas. Indo além dos textos da revisão, é possível recuperar, na discussão de pesquisadoras feministas como Oakley (1981), uma crítica ao paradigma "tradicional" das relações no campo, de modo a justificar a resposta sincera à pergunta do estudante sobre minha posição política. Aqui, se trata de outro âmbito da reciprocidade, ou seja, se o pesquisador deseja saber sobre experiências, crenças e opiniões de determinados indivíduos e grupos, deve também estar preparado para falar sobre essas questões, se for indagado pelos participantes.

Isso não precisa estar relacionado à superexposição do pesquisador, nem a simular um grau de amizade inexistente. Entretanto, a escuta atenta e a atitude de respeito com os pesquisados, aquém ou além do rapport, é fundamental. Avalio, agora, que a pergunta sobre minha posição política tinha, também, algo de teste pessoal, pois, como notam Hammersley e Atkinson (2007), com frequência os participantes têm mais interesse no pesquisador do que no projeto de pesquisa. Mas, na situação em análise, o âmago da pergunta estava ligado a saber se eu era confiável. Nessa perspectiva, ter falado a verdade foi a opção mais consequente, reforçando o discurso anterior de preocupação com o participante, em termos do anonimato e confidencialidade das informações.

A confiança e, portanto, a capacidade de obter melhores dados, em processos mais imersivos de pesquisa, estará ligada também à dimensão temporal do 


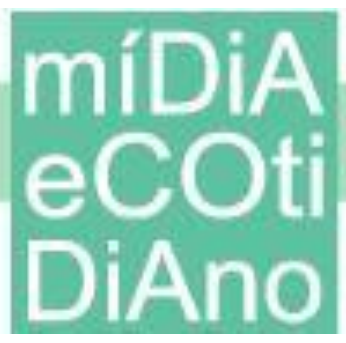

relacionamento (PILKINGTON, 2016) e à possível participação do investigador em várias atividades e contextos de um grupo (BIZEUL, 2019).

Concluindo, vale notar que o artigo possui limitações, sendo a mais relevante o fato de que se concentra apenas em alguns pontos de um tema multidimensional. Isso se justificou pelo formato (tamanho) de artigo científico e pelo processo de construção de questões de pesquisa a partir da investigação em andamento. Outras indagações relevantes apontadas pela literatura revista são: a possibilidade do pesquisador dar, inadvertidamente, respeitabilidade e coerência a ideologias perigosas (BLEE, 1998, 2006) ou desconexas ${ }^{8}$; os possíveis riscos e ataques, inclusive no meio digital, que o pesquisador pode sofrer (MASSANARI, 2018), bem como os impactos emocionais de lidar com falas e mensagens violentas (ASKANIUS, 2019; WALDNER; DOBRATZ, 2019) e a aplicabilidade da proteção à privacidade de grupos que cometem atos ilegais ou violentos (BLEE; CREASAP, 2017). Essas questões poderão ser rotas para outros estudos. Outro desdobramento sugerido é uma comparação mais sistemática entre os problemas ético-metodológicos da pesquisa com movimentos de direita e de esquerda.

Os debates éticos acompanham as transformações sociais e é certo que a mídia digital amplia questionamentos, o que requer a discussão de experiências empíricas (FACIOLI; PADILHA, 2019). É possível recomendar, para o aperfeiçoamento ético dos projetos, "práticas de compartilhamento de experiências, exposição de dilemas e dificuldades a respeito dos problemas" (GILLAN; PICKERILL, 2012, p. 134, tradução nossa). Foi nessa perspectiva que este trabalho procurou dar uma contribuição.

\section{Agradecimentos}

Agradeço aos estudantes de graduação Mayana Yumi Souza dos Reis (que esteve no encontro da UNECON) e Marcelo dos Santos Marcelino, bolsistas de iniciação científica do Programa Unificado de Bolsas de Estudos da Universidade de São Paulo (PUB-USP), em diferentes etapas da pesquisa que deu origem a esse texto, pelas discussões e leitura do manuscrito, bem como à também estudante, de mesmo nível e

${ }^{8}$ Por esse motivo, houve um debate sobre a conveniência de atender o pedido do terrorista norueguês Anders Behring Breivik para ser entrevistado por cientistas (ERIKSSON, 2016). 
instituição, Bruna Correia, pelo apoio na distribuição do questionário de contato com os estudantes de direita. Os avaliadores do artigo fizeram comentários que permitiram aperfeiçoar a discussão.

\section{Referências}

ASKANIUS, T. Studying the Nordic Resistance Movement: three urgent questions for researchers of contemporary neo-Nazis and their media practices. Media, Culture \& Society, Newbury Park, v. 41, n. 6, p. 878-888, 2019.

BARBOSA, S.; MILAN, S. Do not harm in private chat apps: ethical issues for research on and with WhatsApp. Westminster Papers in Communication and Culture, Londres, v. 14, n. 1, p. 49-65, 2019.

BIZEUL, D. Reporting the "good deeds" of far-right activists. In: TOSCANO, E. (ed.).

Researching far-right movements: ethics, methodologies, and qualitative inquiries. Londres: Routledge, 2019. Edição Kindle.

BLEE, K. M. Empathy, and ethics: lessons from oral histories of the Klan. The Journal of American History, Oxford, v. 80, n. 2, p. 596-606, 1993.

BLEE, K. M. White-knuckle research: emotional dynamics in fieldwork with racist activists. Qualitative Sociology, Berlim, v. 21, n. 4, p. 381-398, 1998.

BLEE, K. M. Can we learn from racists? Mobilization, San Diego, v. 11, n. 4, p. 479-482, 2006.

BLEE, K. M. Ethnographies of the far right. Journal of Contemporary Ethnography, Newbury Park, v. 36, n. 2, p. 119-128, 2007.

BLEE, K. M.; CREASAP, K. A. Conservative and right-wing movements. Annual Review of Sociology, Palo Alto, v. 36, p. 269-286, 2010.

CEPÊDA, V. A. A nova direita no Brasil: contexto e matrizes conceituais. Mediações, Londrina, v. 23, n. 2, p. 75-122, 2018.

CODATO, A.; BOLOGNESI, B.; ROEDER, K. M. A nova direita brasileira: uma análise da dinâmica partidária e eleitoral do campo conservador. In: VELASCO E CRUZ, S.; KAYSEL, A.; CODAS, G. (orgs.). Direita, volver: o retorno da direita e o ciclo político brasileiro. São Paulo: Ed. Fundação Perseu Abramo, 2015. p. 115-143.

ERIKSSON, M. Doing violence: some reflections on research, affects, and ethics. Graduate Journal of Social Science, Ipswich, v. 12, n. 3, p. 119-127, 2016.

ESS, C. Digital media ethics. Cambridge; Malden: Polity Press, 2009.

ESSEVELD, J.; EYERMAN, R. Which side are you on? Reflections on methodological issues in the study of 'distasteful' social movements. In: DIANI, M.; EYERMAN, R. (eds.). Studying collective action. Londres: Sage, 1992. p. 217-237. 
FACIOLI, L. R. R.; PADILHA, F. A. Ética e pesquisa em ciências sociais: reflexões sobre um campo conectado. Mediações, Londrina, v. 24, n. 1, p. 228-258, jan.-abr. 2019.

FERNANDES, D. C.; MESSENBERG, D. Um espectro ronda o Brasil (à direita). Plural, São Paulo, v. 25, n. 1, p. 1-12, 2018.

FERREIRA, M. F. A ética da investigação em ciências sociais. Revista Brasileira de Ciência Política, Brasília, n. 11, p. 169-191, 2013.

FUCHS, C. "Dear Mr. Neo-Nazi, can you please give me your informed consent so that I can quote your Fascist tweet?": Questions of social media research ethics in online ideology critique. In: MEIKLE, G. (ed.). The Routledge Companion to Media and Activism. Abingdon: Routledge, 2018. p. 385-394.

GILLAN, K.; PICKERILL, J. The difficult and hopeful ethics of research on, and with, social movements. Social Movement Studies, Londres, v. 11, n. 2, p. 133-143, 2012.

GOODWIN, M. J. The rise and faults of the internalist perspective in extreme right studies. Representation, Abingdon, v. 42, n. 4, p. 347-364, 2006.

HAMMERSLEY, M.; ATKINSON, P. Ethnography: principles in practice. 3. ed. Londres; Nova York: Routledge, 2007.

HÅRD AF SEGERSTAD, Y.; KULLENBERG, C.; KASPEROWSKI, D.; HOWES, C. Studying closed communities on-line: digital methods and ethical considerations beyond informed consent and anonymity. In: ZIMMER, M.; KINDER-KURLANDA, K. (eds.). Internet research ethics for the social age: new challenges, cases, and contexts. Berlim: Peter Lang, 2017. p 213-225.

HOOLACHAN, J. Rapport and over-rapport with research participants. In: ATKINSON, P. et al. (eds.). SAGE research methods foundations. Londres: Sage, 2020. DOI: http://dx.doi.org/10.4135/9781526421036826964

KINCAID, J. D. Theorizing the radical right: directions for social movements research on the right-wing social movements. Sociology Compass, Hoboken, v. 11, n. 5, e12469, 2017.

KOZINETS, R. V. Netnography: doing ethnographic research online. Londres: Sage, 2010.

KRAMER, A. D. I.; GUILLORY, J. E.; HANCOCK, J. T. Experimental evidence of massivescale emotional contagion through social networks. PNAS: Proceedings of the National Academy of Sciences of the United States of America, Washington, D.C., v. 111, n. 24, p. 8788-8790, 2014.

LAUDER, M. A. Covert participant observation of a deviant community: justifying the use of deception. Journal of Contemporary Religion, Abingdon, v. 18, n. 2, p. 185-196, 2003.

MARKHAM, A. N. Ethic as method, method as ethic. Journal of Information Ethics, Jefferson, v. 15, n. 2, p. 37-54, 2006.

MARKHAM, A. N.; TIIDENBERG, K.; HERMAN, A. Ethics as methods: doing ethics in the era of big data research - Introduction. Social Media + Society, Newbury Park, 2018. 
MASSANARI, A. L. Rethinking research ethics, power, and the risk of visibility in the era of the "alt-right" gaze. Social Media + Society, Newbury Park, 2018.

MESSENBERG, D. A direita que saiu do armário: a cosmovisão dos formadores de opinião dos manifestantes de direita brasileiros. Revista Sociedade e Estado, Brasília, v. 32, n. 3, p. 621647, 2017.

OAKLEY, A. Interviewing women: a contradiction in terms. In: ROBERTS, H. (ed.). Doing feminist research. Londres: Routledge and Kegan Paul, 1981. p. 30-61.

PIERUCCI, A. F. As bases da nova direita. Novos Estudos, São Paulo, n. 19, p. 26-45, dez. 1987.

PIERUCCI, A. F. As ciladas da diferença. São Paulo: Ed. 34, 1999.

PILKINGTON, H. The contagion of stigma: the ethics and politics of research with the 'far right'. In: PILKINGTON, H. Loud and proud: passion and politics in the English Defence League. Manchester: Manchester University Press, 2016. p. 13-36.

PILKINGTON, H. "Field observer: Simples." Finding a place from which to do close-up research on the "far right". In: TOSCANO, E. (ed.). Researching far-right movements: ethics, methodologies, and qualitative inquiries. Londres: Routledge, 2019. Edição Kindle.

POULSON, S. C.; CASWELL, C. P., GRAY, L. R. Isomorphism, institutional parochialism, and the study of social movements. Social Movement Studies, Abingdon, v. 13, n. 2, p. 222$242,2014$.

RAMBUKKANA, N. The politics of gray data: digital methods, intimate proximity, and research ethics for work on the "alt-right". Qualitative Inquiry, Newbury Park, v. 25, n. 3, p. 312-323, 2019.

ROMANCINI, R. A ética da pesquisa na rede. In: CONGRESSO BRASILEIRO DE CIÊNCIAS DA COMUNICAÇÃO, 33., 2010, Caxias do Sul, RS. Anais... São Paulo: Intercom, 2010. Disponível em http://www.intercom.org.br/papers/nacionais/2010/resumos/R5-23531.pdf. Acesso em 20 abr. 2020.

ROMANCINI, R. "Vamos tirar a educação do vermelho": o Escola Sem Partido nas redes digitais. E-Compós, Brasília, v. 21, n.1, 2018.

ROMANCINI, R.; CASTILHO, F. Strange fruit: the rise of Brazil's 'new right-wing' and the Non-Partisan School Movement, Journal of Alternative and Community Media, Bristol, v. 4, n. 1, p. 7-22, 2019.

SANTOS, F.; TANSCHEIT, T. Quando velhos atores saem de cena: a ascensão da nova direita política no Brasil. Colombia Internacional, Bogotá, n. 99, p. 151-186, 2019.

SCHAFFAR, W.; THABCHUMPON, N. Militant far-right royalist groups on Facebook in Thailand. Methodological and ethical challenges of Internet-based research. In: TOSCANO, E. (ed.). Researching far-right movements: ethics, methodologies, and qualitative inquiries. Londres: Routledge, 2019. Edição Kindle. 
SEIDMAN, G. Sympathy can be awkward too. Mobilization, San Diego, v. 11, n. 4, p. 483486, 2006.

SMYTH, L.; MITCHELL, C. Researching conservative groups: rapport and understanding across moral and political boundaries. International Journal of Social Research

Methodology, Londres, v. 11, n. 5, p. 441-452, 2008.

SNOW, D. Are there really awkward movements or only awkward research relationship?

Mobilization, San Diego, v. 11, n. 4, p. 495-498, 2006.

TOSCANO, E. (ed.). Researching far-right movements: ethics, methodologies, and qualitative inquiries. Londres: Routledge, 2019. Edição Kindle.

TOSCANO, E. Researching far-right movements. An introduction. In: TOSCANO, E. (ed.). Researching far-right movements: ethics, methodologies, and qualitative inquiries. Londres: Routledge, 2019a. Edição Kindle.

TOSCANO, E.; DI NUNZIO, D. The dark side of the field. Doing research on CasaPound in Italy. In: TOSCANO, E. (ed.). Researching far-right movements: ethics, methodologies, and qualitative inquiries. Londres: Routledge, 2019. Edição Kindle.

TYAGI, A. Field, ethics and self: negotiating methodology in a Hindu right wing camp.

Contemporary Social Science, Londres, v. 13, n. 3-4, p. 323-336, 2018.

VELASCO E CRUZ, S. Elementos de reflexão sobre o tema da direita (e esquerda) a partir do Brasil no momento atual. In: VELASCO E CRUZ, S.; KAYSEL, A.; CODAS, G. (orgs.). Direita, volver: o retorno da direita e o ciclo político brasileiro. São Paulo: Ed. Fundação Perseu Abramo, 2015. p. 13-47.

WALDNER, L. K.; DOBRATZ, B. A. Rapport, respect, and dissonance: studying the white power movement in the United States. In: TOSCANO, E. (ed.). Researching far-right movements: ethics, methodologies, and qualitative inquiries. Londres: Routledge, 2019. Edição Kindle.

WIEVIORKA, M. The specificities of researching evil. In: TOSCANO, E. (ed.). Researching far-right movements: ethics, methodologies, and qualitative inquiries. Londres: Routledge, 2019. Edição Kindle. 